\title{
Root Colonization by Phenazine-1-Carboxamide- Producing Bacterium Pseudomonas chlororaphis PCL1391 Is Essential for Biocontrol of Tomato Foot and Root Rot
}

\author{
Thomas F. C. Chin-A-Woeng, Guido V. Bloemberg, Ine H. M. Mulders, Linda C. Dekkers, and \\ Ben J. J. Lugtenberg \\ Leiden University, Institute of Molecular Plant Sciences, Clusius Laboratory, Wassenaarseweg 64, $2333 \mathrm{AL}$ \\ Leiden, The Netherlands. \\ Accepted 12 August 2000.
}

The phenazine-1-carboxamide-producing bacterium Pseudomonas chlororaphis PCL1391 controls tomato foot and root rot caused by Fusarium oxysporum f. sp. radicislycopersici. To test whether root colonization is required for biocontrol, mutants impaired in the known colonization traits motility, prototrophy for amino acids, or production of the site-specific recombinase, Sss/XerC were tested for their root tip colonization and biocontrol abilities. Upon tomato seedling inoculation, colonization mutants of strain PCL1391 were impaired in root tip colonization in a gnotobiotic sand system and in potting soil. In addition, all mutants were impaired in their ability to control tomato foot and root rot, despite the fact that they produce wild-type levels of phenazine-1-carboxamide, the antifungal metabolite previously shown to be required for biocontrol. These results show, for what we believe to be the first time, that root colonization plays a crucial role in biocontrol, presumably by providing a delivery system for antifungal metabolites. The ability to colonize and produce phenazine-1-carboxamide is essential for control of $F$. oxysporum f. sp. radicis-lycopersici. Furthermore, there is a notable overlap of traits identified as being important for colonization of the rhizosphere and animal tissues.

Additional keywords: phenazines, root rot, site-specific recombinase, sss gene.

Pseudomonas chlororaphis PCL1391 protects tomato (Lycopersicon esculentum Mill. cv. Carmello; Novartis Seeds B.V., Enkhuizen, The Netherlands) plants from foot and root rot caused by Fusarium oxysporum (Schlechtend.:Fr.) f. sp. radicis-lycopersici (W. R. Jarvis \& Shoemaker) (Chin-AWoeng et al. 1998). Biocontrol often requires the production of an antifungal metabolite (AFM). In addition, colonization is assumed necessary as the delivery system of the AFM (Lugtenberg and Dekkers 1999). Previously, it was shown that strain PCL1391 produces the AFM phenazine-1-carboxamide

Corresponding author: T. F. C. Chin-A-Woeng;

E-mail: chin@ rulbim.leidenuniv.nl
(PCN) and that production of this compound is crucial for control of the disease because mutants of this strain that lack the ability to produce phenazine also lack the ability to suppress the disease (Chin-A-Woeng et al. 1998).

Several lines of evidence indicate that colonization is often the limiting step in biocontrol (Bull et al. 1991; Schippers et al. 1987; Weller 1988), but direct and satisfactory proof for the role of colonization in biocontrol has not yet been offered because of the lack of colonization mutants. Indeed, in a study on cucumber spermosphere colonization by Enterobacter cloacae, which suppresses Pythium ultimum, it was claimed that colonization is not important for biocontrol (Roberts et al. 1994).

A number of colonization traits have been recently identified for P. fluorescens WCS365 (reviewed in Lugtenberg and Dekkers 1999, and Lugtenberg et al. 1999). We constructed derivatives of PCL1391 impaired in colonization traits to test whether colonization plays a role in control of foot and root rot by this strain. These traits include motility, amino acid synthesis, and site-specific recombination. Motility mutants of strain WCS365 are severely impaired in colonization of the root tip when tested in direct competition with the wild type (de Weger et al. 1987; Dekkers et al. 1998b; Simons et al. 1996). Another trait important for the colonizing ability of strain WCS365 is synthesis of amino acids. Mutants auxotrophic for leucine, arginine, histidine, valine/isoleucine, or tryptophan are unable to colonize tomato root tips efficiently unless the required amino acid is added exogenously to the test system (Simons et al. 1997). An sss/xerC homologue in strain WCS365, identified in a screening of random Tn5lacZ mutants in competition with the parental strain, was shown to be important for efficient root colonization in the tomato, potato, and wheat rhizosphere (Dekkers et al. 1998a). The sss gene in $P$. aeruginosa and xerC in Escherichia coli encode proteins that belong to the lambda integrase family of sitespecific recombinases that play a role in phase variation caused by DNA rearrangement (Höfte et al. 1994). It is assumed that Sss plays a role in generating various subpopulations of WCS365 and that the colonization-defective mutant PCL1233 is frozen in a rhizosphere-incompetent subpopulation. 
Here we describe the construction of PCL1391 derivatives impaired in the colonization traits motility, amino acid prototrophy, and site-specific recombination as well as the analysis of the ability of these mutants to colonize the tomato root system and to control tomato foot and root rot caused by $F$. oxysporum f. sp. radicis-lycopersici.

\section{RESULTS}

Isolation of auxotrophic and nonmotile mutants of $\boldsymbol{P}$. chlororaphis PCL1391.

To obtain colonization mutants of PCL1391, various strategies were followed. Three auxotrophic mutants of $P$. chlororaphis PCL1391 were obtained after screening 400 PCL1391::Tn5lacZ transconjugants on King's medium B (KB) and standard succinate medium (SSM). Testing the mutants on SSM supplemented with amino acids revealed that the mutants were auxotrophic for phenylalanine, methionine, or tryptophan, respectively. Similarly, two other transconjugants were found to be completely impaired in swarm formation. The phenylalanine auxotrophic mutant strain, PCL1128, and one of the motility mutants, PCL1131, were chosen for further study.

\section{Construction of an sss mutant of strain PCL1391.}

A P. fluorescens WCS365 derivative mutated in the sss gene is known to be impaired in its competitive colonizing ability (Dekkers et al. 1998a). Two primers were designed on the basis of the most conserved sequences in the protein sequence of known sss and xerC genes of $P$. fluorescens, $P$. aeruginosa, and E. coli (Fig. 1) and used in a polymerase chain reaction (PCR) with genomic DNA of $P$. chlororaphis PCL1391. As a result, a 0.3-kb DNA fragment was amplified. The nucleotide sequence of the fragment was determined and shown to have $63 \%$ identity with that of the sss gene of $P$. fluorescens WCS365 (Dekkers et al. 1998a), 65\% with that of $P$. aeruginosa (Höfte et al. 1994), and 58\% with that of the $E$. coli xerC gene (Colloms et al. 1990). The obtained ssshomologous DNA fragment was cloned into pIC20R with a tetracycline cassette. The resulting construct, pMP6009, was used as a suicide construct for homologous recombination after transfer to strain PCL1391. Integration of pMP6009 was confirmed by Southern hybridization with the sss PCR fragment as a probe (results not shown).

\section{Production of extracellular metabolites and colonizing ability of mutants of PCL1391.}

The PCL1391 mutants in motility (PCL1131), prototrophy (PCL1128), and an sss homologue (PCL1126) were not altered in their production of the extracellular metabolites hydrogen cyanide, chitinase, protease, and PCN (data not shown). An in vitro petri dish assay was used to show that the mutants possess antifungal activity against $F$. oxysporum $\mathrm{f}$. sp. radicis-lycopersici to the same extent as the wild type (data not shown). The colonizing ability of the PCL1391 mutants generated was tested in competition against the wild-type strain PCL1391 or against the Tn5lacZ-tagged derivative PCL1392 in a gnotobiotic sand system (Simons et al. 1996). The use of strain PCL1392 allows us to distinguish the competing strain from the newly constructed mutants when growing on KB containing kanamycin and X-Gal. The Tn5lacZ insertion has no impact on colonization behavior because strain PCL1392 was able to compete fully with the untagged wild-type strain (Fig. 2A). The colonization ability of the three putative colonization mutants was assayed in the gnotobiotic sand system in which strain PCL1131 (motilitydeficient) and PCL1128 (phe) were inoculated in a 1:1 ratio with the wild-type strain PCL1391 on germinated tomato seeds. Since strain PCL1126 (sss) does not carry a lacZ reporter gene, this strain was tested against PCL1392. The non-

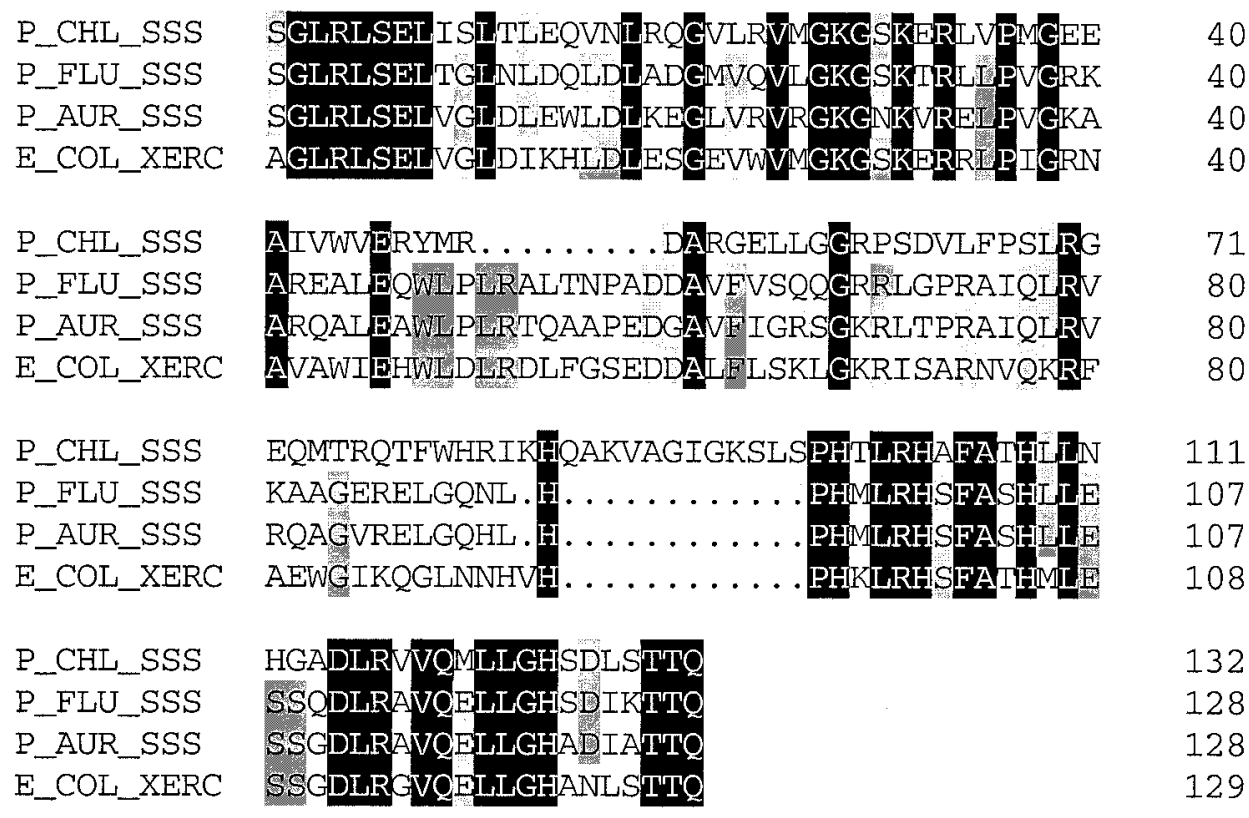

Fig. 1. Alignment of the amino acid sequence deduced from the 0.3-kb DNA fragment of Pseudomonas chlororaphis PCL1391 obtained with the use of polymerase chain reaction homologous to the sss genes of P. fluorescens WCS365 (Dekkers et al. 1998a) and P. aeruginosa 7NSK2 (Höfte et al. 1994) and xerC of Escherichia coli (Colloms et al. 1990). 
motile strain PCL1131 and the phe mutant PCL1128 were impaired in colonization at least 1,000-fold compared with the wild type (Fig. 2A). The sss mutant (PCL1126) was impaired 50 -fold in its ability to compete with the lacZ-tagged wildtype strain (Fig. 2A).

Colonization in nonsterile potting soil was tested after application of single strains on germinated seeds. The presence of the nonmotile mutant PCL1131 and phe mutant PCL1128 at the root tip was below the detection limit of $2.7 \log _{10}(\mathrm{CFU}+$ $1) / \mathrm{cm}$ of root tip. Therefore, these strains are impaired by at least 1,000-fold compared with the parental strain (Fig. 2B). Colonization by the sss mutant PCL1126 was about 10-fold
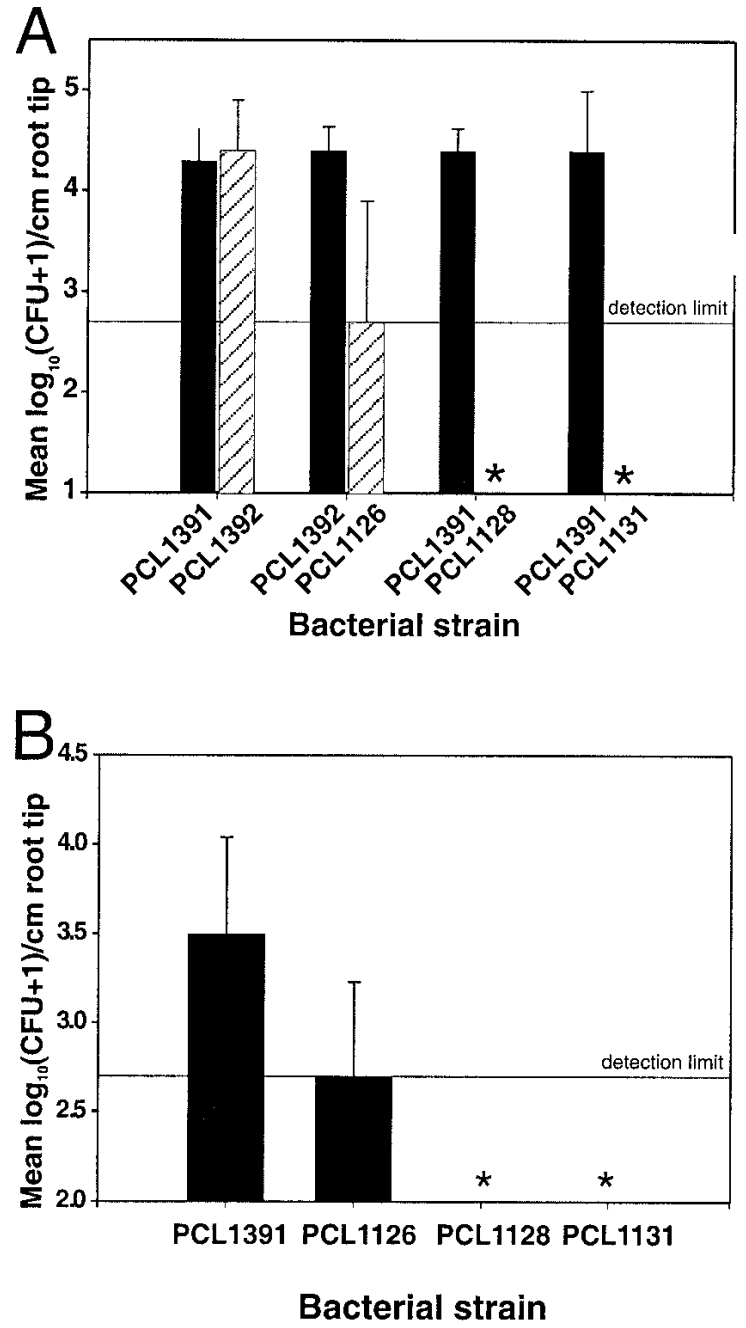

Fig. 2. Tomato root tip colonizing ability of Pseudomonas chlororaphis PCL1391 and derivatives in a gnotobiotic sand system and in soil. The bars indicate the number of bacteria recovered from the last $1 \mathrm{~cm}$ of the tomato root tip either in competitive colonization in a gnotobiotic system (A) or singly in unsterilized potting soil (B). The standard error is indicated on top of the bars. $*=$ counts below the detection limit of $2.7 \log _{10}(\mathrm{CFU}+1) / \mathrm{cm}$ of root tip. The number of bacteria on the root tip was determined 7 days after inoculation by dilution plating on King's medium B containing X-Gal. Values were calculated from 20 plants. A, Colonization of the root tip after tomato seedlings were inoculated with a 1:1 ratio of mutant and PCL1391 (or the Tn5lacZ-tagged derivative PCL1392) and grown in the gnotobiotic sand system. B, Colonization of the root tip when seedlings were inoculated singly with the colonization mutant and grown in potting soil. lower $\left(2.7 \pm 0.5 \log _{10}[\mathrm{CFU}+1] / \mathrm{cm}\right.$ of root tip) than that of the wild-type strain $\left(3.5 \pm 0.5 \log _{10}[\mathrm{CFU}+1] / \mathrm{cm}\right.$ of root tip) (Fig. 2B).

\section{Biocontrol of colonization mutants.}

Biocontrol ability of PCL1391 and its mutant derivatives was tested against $F$. oxysporum f. sp. radicis-lycopersici on tomato (Chin-A-Woeng et al. 1998). When no bacteria were applied to the seeds, $74 \%$ of the plants were diseased after 16 days, whereas seed coating with the wild-type strain PCL1391 reduced the percentage of diseased plants to $33 \%$ (Fig. 3). Coating the seeds with the motility-impaired mutant PCL1131 or the phe auxotrophic mutant PCL1128 did not reduce the disease significantly compared with inoculated control. Similarly, inoculation with the sss mutant strain PCL1126 did not result in disease control. The results show that colonization mutants PCL1126 (sss), PCL1128 (phe), and PCL1131 (motility-deficient) are severely impaired in their ability to suppress foot and root rot caused by $F$. oxysporum f. sp. radicislycopersici.

\section{DISCUSSION}

A number of colonization mutants of biocontrol strain $P$. chlororaphis PCL1391 were constructed on the basis of traits previously described as being important for the colonizing ability of $P$. fluorescens WCS365 (Lugtenberg and Dekkers 1999). In the present study, mutants in three established colonization traits-loci, motility, amino acid prototrophy, and sss, were constructed in strain PCL1391 and all appeared impaired in root colonization (Fig. 2). Corresponding mutants of strain WCS365 are also impaired in root colonization. Previously, nonmotile mutants of $P$. fluorescens WCS374 and $P$. putida WCS358 were also shown to be impaired in their ability to colonize the lower parts of tomato and potato (de Weger et al. 1987; Simons et al. 1996). We conclude that these three colonization traits are important not only in strain WCS365, but in other biocontrol strains as well.

It was shown that production of $\mathrm{PCN}$ by $P$. chlororaphis PCL1391 is essential for the biocontrol activity against $F$. oxysporum $\mathrm{f}$. sp. radicis-lycopersici in a tomato- $F$. oxysporum assay system (Chin-A-Woeng et al. 1998). We have shown that the three newly constructed colonization mutants did not control disease, despite the fact that they showed normal antifungal activity in vitro and produced wild-type amounts of PCN. The lack of biocontrol activity by the three different colonization mutant strains (Fig. 3) shows that root colonization is a crucial factor in the disease suppression mediated by PCL1391. We believe that this is the first study in which a direct role for the root colonization ability of a biocontrol strain in disease suppression is shown.

Although we showed that PCN production in vitro was the same for the wild-type and colonization mutants, we did not pursue the quantitative analysis of PCN produced per colonyforming units in the rhizosphere for several reasons. First, on the basis of how we think biocontrol is achieved by Pseudomonas bacteria, we believe that what really matters is not the total production on the root system, but the minimally required local concentration of the antifungal factor produced at the right time and place. In addition, production of PCN is regulated by cell density-dependent regulatory mechanisms 
(unpublished results). Second, because we tested three mutants that were mutated in traits involved in independent physiological roles, we do not have reason to expect that all three colonization mutants would differ from the parental strain by producing different amounts in the rhizosphere. With respect to the reisolation of phenazine from the tomato root system, we failed in our attempts to quantify PCN in the rhizosphere after colonization by the wild-type strain. We expect the total amount of phenazines produced on the root system by the colonization mutants to be even lower than that produced by the wild type as a result of the lower numbers on the root.

It would be interesting to use the same approach used to show the role of colonization in biocontrol in order to test the importance of colonizing ability in other applications of microbial inoculants of seeds (biofertilizers, phytostimulators, and phytoremediators) in which the effectiveness of an inoculant is likely to be dependent on the establishment of a minimum population size.

The three colonization traits shown here to be important for biocontrol of the plant disease tomato root and foot rot also play a role in the colonization of animal tissues by bacteria (Chiang and Mekalanos 1998; Drake and Montie 1988; Lugtenberg and Dekkers 1999; Rijpkema et al. 1992; Weiser et al. 1990). Phenazine derivatives do not only kill fungi, but the phenazine-derivative pyocyanine, produced by $P$. aeruginosa, is also involved in killing animal cells and tissues (Mahajan et al. 1999). The two established biocontrol traits of $P$. chlororaphis PCL1391, colonization and production of phenazine antibiotics, are bacterial traits that also play a role in colonization of animal tissues and in killing of animal cells, respectively. We suggest, therefore, that these bacterial traits are important in interactions with widely different eukaryotes and must have been developed early in evolution.

\section{MATERIALS AND METHODS}

Microorganisms and media.

The bacterial strains and plasmids used are listed in Table 1. KB was used routinely (King et al. 1954) for culturing Pseudomonas strains at $28^{\circ} \mathrm{C}$. E. coli was grown in Luria-Bertani (LB) medium (Sambrook et al. 1989). F. oxysporum f. sp.

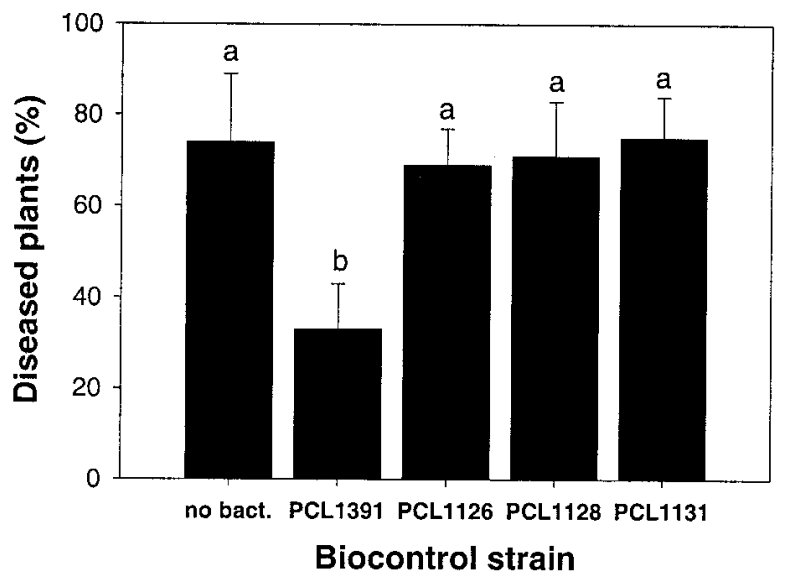

Fig. 3. Biocontrol of Pseudomonas chlororaphis PCL1391 and its root colonization-impaired derivatives. Strains PCL1391 (wild type), PCL1126 (sss), PCL1128 (phe), and PCL1131 (motility impaired) were tested in a Fusarium oxysporum f. sp. radicis-lycopersici-tomato test system. Tomato seeds were coated with bacteria and grown in potting soil infected with $F$. oxysporum spores $\left(2 \times 10^{6}\right.$ spores $/ \mathrm{kg}$ of soil $)$ under controlled conditions. Percentage of diseased plants was determined 16 days after inoculation. Per strain, 100 plants in 10 trays of 10 plants were tested. Data were analyzed for significance with variance analysis followed by Fisher's least-significant-difference test $(\alpha=0.05)$. Values with different letter indications demonstrate a statistically significant difference.

Table 1. Microorganisms and plasmids

\begin{tabular}{|c|c|c|}
\hline Strains and plasmids & Relevant characteristics & Reference or source \\
\hline \multicolumn{3}{|l|}{ Bacterial strains } \\
\hline PCL1391 & $\begin{array}{l}\text { Wild-type Pseudomonas chlororaphis. Isolated from tomato } \\
\text { rhizosphere; biocontrol strain of tomato foot and root rot }\end{array}$ & Chin-A-Woeng et al. 1998 \\
\hline PCL1392 & $\begin{array}{l}\text { PCL1391 derivative tagged with } l a c Z \text { and } \mathrm{Km}^{\mathrm{r}} \\
\text { with wild-type colonizing ability }\end{array}$ & This study \\
\hline PCL1126 & $\begin{array}{l}\text { PCL1391 derivative with a mutation in an sss homologous } \\
\text { gene, } \mathrm{Tc}^{\mathrm{r}}\end{array}$ & This study \\
\hline PCL1128 & $\begin{array}{l}\text { Tn5lacZ-derivative of strain PCL1391 auxotrophic for phe n- } \\
\text { ylalanine, } \mathrm{Km}^{\mathrm{r}}\end{array}$ & This study \\
\hline PCL1131 & $\begin{array}{l}\text { Tn5lacZ-derivative of strain PCL1391 impaired in motility, } \\
\mathrm{Km}^{\mathrm{r}}\end{array}$ & This study \\
\hline S17-1 & $\begin{array}{l}\text { Escherichia coli MM294, RP4-2 Tc::Mu-Km::Tn7 chromo- } \\
\text { somally integrated }\end{array}$ & Simon et al. 1983 \\
\hline DH5 $\alpha$ & $\begin{array}{l}\text { endA1 gyrSA96 } \mathrm{hrdR} 17(\mathrm{rK}-\mathrm{mK}-) \text { supE44 recAl; general } \\
\text { purpose } E \text {. coli host strain used for transformation and } \\
\text { propagation of plasmids }\end{array}$ & Boyer and Roulland-Dussoix 1969 \\
\hline \multicolumn{3}{|l|}{ Fungus } \\
\hline $\begin{array}{l}\text { Fusarium oxysporum f. sp. radicis- } \\
\text { lycopersici strain ZUM2407 }\end{array}$ & Cause of foot and root rot of tomato & $\begin{array}{l}\text { IPO-DLO, Wageningen, } \\
\text { The Netherlands }\end{array}$ \\
\hline \multicolumn{3}{|l|}{ Plasmids } \\
\hline pCIB100 & Plasmid harboring promoterless Tn 5 lac Z transposon & Lam et al. 1990 \\
\hline pMP6009 & $\begin{array}{l}\text { pIC20R-based suicide construct with a } 0.3-\mathrm{kb} \text { DNA fragment } \\
\text { of the sss gene of strain PCL1391 and a Tc }{ }^{\mathrm{r}} \text { cassette in- } \\
\text { serted in the multicloning site with PstI/XbaI }\end{array}$ & This study \\
\hline pMP5000 & $\begin{array}{l}\text { pIC20R with a Tcr cassette inserted in the multicloning site } \\
\text { with PstI/SalI }\end{array}$ & van der Bij et al. 1996 \\
\hline
\end{tabular}


radicis-lycopersici was stock cultured on potato dextrose agar (Difco Laboratories, Detroit, MI, U.S.A.) and grown in Czapek Dox liquid medium (Difco Laboratories) at $28^{\circ} \mathrm{C}$. Media were solidified with $1.8 \%$ agar when necessary. We added $50 \mu \mathrm{g}$ of kanamycin, $80 \mu \mathrm{g}$ of tetracycline, and $50 \mu \mathrm{g}$ of carbenicillin per $\mathrm{ml}$ for antibiotic selection where applicable. To screen for $\beta$-galactosidase production, KB or LB medium was supplemented with 5-bromo-4-chloro-3-indolyl- $\beta$-galactopyranoside (X-Gal) at a concentration of $40 \mu \mathrm{g} / \mathrm{ml}$.

\section{DNA modifications.}

Digestions with restriction endonucleases, ligation, and transformation of $E$. coli cells with plasmid DNA were performed by standard molecular biological protocols (Sambrook et al. 1989). Nucleotide sequencing was performed by Eurogentec B.V. (Herstal, Belgium) with AB1377-based fluorescent-sequencing technology. Computer analysis of protein and nucleotide sequences was performed with Wisconsin Package version 10.0 (Genetics Computer Group, Madison, WI, U.S.A).

\section{Construction of mutants of strain PCL1391.}

P. chlororaphis PCL1391::Tn5lacZ transconjugants were constructed by two-parental mating of strains PCL1391 and E. coli S17-1 (Lam et al. 1990). The latter strain harbors plasmid pCIB100 that carries a Tn5lacZ transposon. Auxotrophic transconjugants were isolated after screening PCL1391::Tn5lacZ colonies on KB and SSM (Meyer 1978). The mutants that grew on KB but not on SSM were further characterized for their auxotrophies. To this end, colonies were transferred to SSM plates containing a single amino acid $(10 \mathrm{mg} / \mathrm{l})$, after which growth was evaluated.

To screen for nonmotile mutants, spot inoculation and growth on semisolid $\mathrm{KB}$ (1/20 strength $\mathrm{KB}$ and $0.3 \%$ agar) was used. After growth overnight, the wild-type strain PCL1391 formed swarming zones of approximately $2 \mathrm{~cm}$ in diameter, whereas growth of nonmotile mutants remained restricted to the site of inoculation.

To construct mutants in an sss homologue, two primers oMP489 5'GGAAGATCTGGCCTGCGGCTCTCCGAGCT$\left.3^{\prime}\right)$ and oMP490 (5'-CAGGTGGGTGTAGATCTGGGTGGT$\left.3^{\prime}\right)$ were used in a PCR with genomic DNA of strain PCL1391 to obtain a DNA fragment homologous with the $P$. fluorescens WCS365 sss gene. The 0.3-kb DNA fragment obtained was cloned into the multicloning site of pIC20R by the $B g l \mathrm{II}$ restriction sites incorporated in the primers (underlined). A tetracycline cassette, excised from pMP5000 by Pst I/XbaI, was cloned next to the DNA fragment. The resulting construct, pMP6009, was transferred to strain PCL 1391 by electroporation. After incubation for $16 \mathrm{~h}$ at $28^{\circ} \mathrm{C}$, the cells were plated onto selective medium. Tetracycline-resistant transformants were tested for insertion by homologous recombination in an sss-homologous gene with Southern hybridization and the sss PCR fragment as a probe. The detection of production of the extracellular metabolites hydrogen cyanide, chitinase, protease, and PCN and the in vitro petri dish antifungal assay against $F$. oxysporum f. sp. radicis-lycopersici were performed as described (Chin-A-Woeng et al. 1998).

Colonization assays in a gnotobiotic sand system and in soil.

Colonization assays were performed as described previously (Simons et al. 1996). A 1:1 bacterial mixture from over- night cultures of wild type and mutant (one was tagged with the lac $Z$ reporter) was prepared, and a tomato seedling with a root of 2 to $3 \mathrm{~mm}$ was incubated in it for $15 \mathrm{~min}$. This inoculation method results in the introduction of $10^{4}$ to $10^{5} \mathrm{CFU}$ onto the seedling. The seedlings were subsequently planted in a tube containing a sterile mixture of sand and $10 \%$ (vol/wt) plant nutrient solution (Hoffland et al. 1989). Plants were grown for 7 days after which $1 \mathrm{~cm}$ of the root tip was removed and shaken vigorously in $1 \mathrm{ml}$ of phosphate-buffered saline (PBS) on an Eppendorf shaker (Eppendorf, Hamburg, Germany) to remove the bacteria from the root. The suspension was plated onto $\mathrm{KB}-\mathrm{X}-\mathrm{Gal}$ agar with a spiral plater (Spiral Systems Inc., Cincinnati, OH, U.S.A.) to determine the numbers of lacZ-tagged and untagged bacteria in the suspension with the use of blue-white screening.

The colonization behavior of individual strains in potting soil was determined by the same growth system as described, except that the sterile sand was replaced by a mixture of sand and nonsterile potting soil (Jongkind Grond B.V., Aalsmeer, The Netherlands) (1:3 wt/wt). The bacteria recovered from the tip were plated on KB containing X-Gal, cycloheximide (100 $\mu \mathrm{g} / \mathrm{ml})$, carbenicillin, and kanamycin or tetracycline. Strains were either identified by blue staining (lacZ) or formation of a green pigment, typically for strain PCL1391. For every strain, 20 plants were analyzed and all experiments were performed twice.

\section{Biocontrol ability of bacterial strains.}

Biocontrol experiments were performed as described previously (Chin-A-Woeng et al. 1998). Tomato seeds were inoculated in a suspension of $1 \times 10^{9} \mathrm{CFU} / \mathrm{ml}$ of biocontrol bacteria in $1 \%(\mathrm{wt} / \mathrm{vol})$ methylcellulose in water and dried under an airflow. Subsequent removal of the bacteria from the coated seeds by shaking vigorously in $1 \mathrm{ml}$ of PBS and dilution plating on KB showed on average $10^{3}$ to $10^{4} \mathrm{CFU}$ per seed. Seeds coated with bacteria were individually sown in small pots containing potting soil infected with $F$. oxysporum f. sp. radicis-lycopersici spores $\left(2 \times 10^{6}\right.$ spores $/ \mathrm{kg}$ of soil $)$. Plants were grown in a greenhouse at $21^{\circ} \mathrm{C}$ with $70 \%$ relative humidity and $16 \mathrm{~h}$ of daylight. For each strain, 100 plants were tested in 10 trays of 10 plants, and plants were watered from the bottom. After 16 days, plants were removed from the pots and examined for root and foot rot, as shown by the presence of browning and lesions. Roots without any disease symptoms were classified as healthy. Data were analyzed for significance with variance analysis, followed by Fisher's least-significantdifference test $(\alpha=0.05)$, which was performed with SPPS software (SPSS Inc., Chicago, IL, U.S.A.). All experiments were performed at least twice.

\section{ACKNOWLEDGMENTS}

We thank D. de Witt for technical assistance in the tomato-F. oxysporum f. sp. radicis-lycopersici biocontrol assays. This work was financially supported by the EU-Biotech program (contract BI04CT96.0181).

\section{LITERATURE CITED}

Boyer, H. W., and Roulland-Dussoix, D. 1969. A complementation analysis of the restriction and modification of DNA in Escherichia coli. J. Mol. Biol. 41:459-472. 
Bull, C. T., Weller, D. M., and Thomashow, L. S. 1991. Relationship between root colonization and suppression of Gaeumannomyces graminis var. tritici by Pseudomonas fluorescens strain 2-79. Phytopathology 81:954-959.

Chiang, S. L., and Mekalanos, J. J. 1998. Use of signature-tagged transposon mutagenesis to identify Vibrio cholerae genes critical for colonization. Mol. Microbiol. 27:797-805.

Chin-A-Woeng, T. F. C., Bloemberg, G. V., van der Bij, A. J., van der Drift, K. M. G. M., Schripsema, J., Kroon, B., Scheffer, R. J., Keel, C., Bakker, P. A. H. M., Tichy, H.-V., de Bruijn, F. J., Thomas-Oates, J. E., and Lugtenberg, B. J. J. 1998. Biocontrol by phenazine-1carboxamide-producing Pseudomonas chlororaphis PCL1391 of tomato root rot caused by Fusarium oxysporum f. sp. radicislycopersici. Mol. Plant-Microbe Interact. 11:1069-1077.

Colloms, S. D., Sykora, P., Szatmari, G., and Sherratt, D. J. 1990. Recombination at ColE1 cer requires the Escherichia coli xerC gene product, a member of the lambda integrase family of site-specific recombinase. J. Bacteriol. 172:6973-6980.

de Weger, L. A., van der Vlught, C. I. M., Wijfjes, A. H. M., Bakker, P. A. H. M., Schippers, B., and Lugtenberg, B. J. J. 1987. Flagella of a plant growth-stimulating Pseudomonas fluorescens strain are required for colonization of potato roots. J. Bacteriol. 169:2769-2773.

Dekkers, L. C., Phoelich, C. C., van der Fits, L., and Lugtenberg, B. J. J. 1998a. A site-specific recombinase is required for competitive root colonization by Pseudomonas fluorescens WCS365. Proc. Natl. Acad. Sci. USA 95:7051-7056.

Dekkers, L. C., van der Bij, A. J., Mulders, I. H. M., Phoelich, C. C., Wentwoord, R. A. R., Glandorf, D. C. M., Wijffelman, C. A., and Lugtenberg, B. J. J. 1998b. Role of the O-antigen of lipopolysaccharide, and possible roles of growth rate and of NADH:ubiquinone oxidoreductase (nuo) in competitive tomato root-tip colonization by Pseudomonas fluorescens WCS365. Mol. Plant-Microbe Interact. 11:763-771.

Drake, D., and Montie, T. C. 1988. Flagella, motility and invasive virulence of Pseudomonas aeruginosa. J. Gen. Microbiol. 134:43-52.

Hoffland, E., Findenegg, G. R., and Nelemans, J. A. 1989. Solubilization of rock phosphate by rape. Plant Soil 113:161-165.

Höfte, M., Dong, Q., Kourambas, S., Krishnapillai, V., Sherratt, D., and Mergeay, M. 1994. The sss gene product, which affects pyoverdin production in Pseudomonas aeruginosa 7NSK2, is a site-specific recombinase. Mol. Microbiol. 14:1011-1020.

King, E. O., Ward, M.K., and Raney, D.E. 1954. Two simple media for the demonstration of pyocyanin and fluorescein. J. Lab. Clin. Med. 44:301-307.

Lam, S. T., Ellis, D. M., and Ligon, J. M. 1990. Genetic approaches for studying rhizosphere colonization. Plant Soil 129:11-18.

Lugtenberg, B. J. J., and Dekkers, L. C. 1999. What makes Pseudomonas bacteria rhizosphere competent? Environ. Microbiol. 1:9-13.

Lugtenberg, B. J. J., Dekkers, L. C., Bansraj, M., Bloemberg, G. V.,
Camacho, M., Chin-A-Woeng, T. F. C., van den Hondel, C., Kravchenko, L., Kuiper, I., Lagopodi, A. L., Mulders, I., Phoelich, C., Ram, A., Tikhonovich, I., Tuinman, S., Wijffelman, C., and Wijfjes, A. 1999. Pseudomonas genes and traits involved in tomato root colonization. Pages 324-330 in: Biology of Plant-Microbe Interactions, Vol. 2. P. J. G. M. de Wit, T. Bisseling, and W. J. Stiekema, eds. International Society for Molecular Plant-Microbe Interactions, St. Paul, MN, U.S.A.

Mahajan, M. S., Tan, M. W., Rahme, L. G., and Ausubel, F. M. 1999. Molecular mechanisms of bacterial virulence elucidated using a Pseudomonas aeruginosa Caenorhabditis elegans pathogenesis model. Cell 96:47-56.

Meyer, J. M. 1978. The fluorescent pigment of Pseudomonas fluorescens: Biosynthesis, purification and physicochemical properties. J. Gen. Microbiol. 107:319-328.

Rijpkema, S. G., Bik, E. M., Jansen, W. H., Gielen, H., Versluis, L. F., Stouthamer, A. H., Guinee, P. A., and Mooi, F. R. 1992. Construction and analysis of a Vibrio cholerae delta-aminolevulinic acid auxotroph which confers protective immunity in a rabbit model. Infect. Immun. 60:2188-2193.

Roberts, D. P., Short, N. M. J., Maloney, A. P., Nelson, E. B., and Schaff, D. A. 1994. Role of colonization in biocontrol: Studies with Enterobacter cloacae. Plant Sci. 101:83-89.

Sambrook, J., Fritsch, E. F., and Maniatis, T. 1989. Molecular Cloning: A Laboratory Manual. Cold Spring Harbor Laboratory Press, Cold Spring Harbor, NY.

Schippers, B., Lugtenberg, B. J. J., and Weisbeek, P. J. 1987. Plan growth control by fluorescent pseudomonads. Pages 19-39 in: Innovative Approaches to Plant Disease Control. I. Chet, ed. Wiley, NY.

Simon, R., Priefer, U., and Puhler, A. 1983. A broad host range mobilization system for in vivo genetic engineering: Transposon mutagenesis in Gram negative bacteria. Bio/Technology. 1:784-791.

Simons, M., Permentier, H. P., de Weger, L. A., Wijffelman, C. A., and Lugtenberg, B. J. J. 1997. Amino acid synthesis is necessary for tomato root colonization by Pseudomonas fluorescens strain WCS365. Mol. Plant-Microbe Interact. 10:102-106.

Simons, M., van der Bij, A. J., Brand, I., de Weger, L. A., Wijffelman, C. A., and Lugtenberg, B. J. J. 1996. Gnotobiotic system for studying rhizosphere colonization by plant growth-promoting Pseudomonas bacteria. Mol. Plant-Microbe Interact. 9:600-607.

van der Bij, A. J., de Weger, L. A., Tucker, W. T., and Lugtenberg, B. J. J. 1996. Plasmid stability in Pseudomonas fluorescens in the rhizosphere. Appl. Environ. Microbiol. 62:1076-1080.

Weiser, J. N., Williams, A., and Moxon, E. R. 1990. Phase-variable lipopolysaccharide structures enhance the invasive capacity of Haemophilus influenzae. Infect. Immun. 58:3455-3457.

Weller, D. M. 1988. Biological control of soilborne plant pathogens in the rhizosphere with bacteria. Annu. Rev. Phytopathol. 26:379-407. 